\title{
THE ORIGIN OF SPLITTING PHENOMENA IN THE MARTENSITIC TRANSFORMATION OF STAINLESS STEELS
}

\author{
F. G. CABALLERO, L. F. ÁLVAREZ, C. CAPDEVILA and C. GARCÍA DE ANDRÉS \\ Solid-Solid Phase Transformation Group (GITFES), Department of Physical Metallurgy, Centro \\ Nacional de Investigaciones Metalúrgicas (CENIM), Consejo Superior de Investigaciones \\ Científicas (CSIC), Avda. Gregorio del Amo, 8, 28040 Madrid, Spain, www.cenim.csic.es
}

Keywords: Stainless steels, Martensitic phase transformation

\begin{abstract}
Under certain conditions, martensite transformation splits into different and successive stages identified by high resolution dilatometry. The experimental results of this study show that, in the absence of carbide precipitation, this phenomenon is related to concentration gradients in the austenite produced by the dissolution of carbides during heating.
\end{abstract}

\section{INTRODUCTION}

Several authors reported certain uncommon behaviour during the martensitic transformation of alloyed steels with carbide-forming elements such as chromium, molybdenum, vanadium, and tungsten [1-4]. In these steels, the non-isothermal austenite-martensite transformation does not occurs continuously in a single stage throughout a certain range of temperatures, $M_{s}-M_{f}$. Under certain conditions, this transformation splits into different and successive stages limited by different $M_{s i}$ temperatures. These authors only refer to splitting occurring at temperatures higher than the main martensitic transformation. In this sense, they believe that the splitting is caused by the transformation of areas of austenite with a smaller concentration of carbon and carbide-forming elements than the massive austenite and explain this phenomenon in terms of carbide precipitation during cooling.

However, more recently, splitting phenomena were also detected in the absence of carbide precipitation in stainless steels by high resolution dilatometry [5]. In that case, splitting occurs at temperatures lower than the main martensitic transformation. Authors proposed an explanation to these phenomena elsewhere [5]. This type of splitting is caused by the concentration gradients produced in the austenite from the partial dissolution of carbides during heating. From austenitising states in which austenite has not reached homogenisation, either because the carbide dissolution process has not finished or because concentration gradients have not been eliminated, the nonisothermal austenite-martensite transformation will experience splitting phenomena at temperatures lower than the main martensitic transformation. This splitting indicates the existence of areas of austenite that are enriched in carbon and/or carbide-forming elements in relation to the massive austenite phase. The aim of this work is to show experimental evidences that prove the origin of the splitting phenomenon in the absence of carbide precipitation in stainless steels.

\section{MATERIAL AND HEAT TREATMENTS}

The chemical composition of the studied steel is given in Table 1. The material comes from coldrolled coil and was tested in annealed condition. The as-received microstructure consists of globular carbides finely distributed in a ferrite matrix (Figure 1.a). Measurements of area percent occupied by carbides were performed by means of automatic image analyses. Metallographic samples etched with Murakami's reagent were used for those measurements (Figure 1.b). The area percentage of 
carbides and the mean carbide size measured by this technique in the initial microstructure of the steel are $9.9 \%$ and $0.9 \mu \mathrm{m}$ in diameter, respectively.

Thermodynamic equilibrium calculations using MTDATA [6] in Figure 2 show that only $\mathrm{M}_{23} \mathrm{C}_{6}$ and $\mathrm{M}_{7} \mathrm{C}_{3}$ carbides could be formed and precipitated in the microstructure of this steel. According to calculations the volume fraction of $\mathrm{M}_{7} \mathrm{C}_{3}$ carbides that could be formed is less than $2 \%$ (negligible). X-ray diffraction patterns confirmed only the presence of $\mathrm{M}_{23} \mathrm{C}_{6}$ carbides in the initial microstructure [5].

An Adamel Lhomargy DT1000 high resolution dilatometer was used to analyse the splitting phenomena at two different austenitising states. For this purpose, cylindrical specimens of $2 \mathrm{~mm}$ in diameter and $12 \mathrm{~mm}$ in length were heated at a constant rate of $0.5{ }^{\circ} \mathrm{C} / \mathrm{s}$ at two different austenitisation temperatures, $1060{ }^{\circ} \mathrm{C}$ and $1200{ }^{\circ} \mathrm{C}$. After a holding time of $60 \mathrm{~s}$, specimens were cooled at a rate of $50{ }^{\circ} \mathrm{C} / \mathrm{s}$. Previous work in this steel showed that this cooling rate is high enough to avoid carbide precipitation during cooling [7]. In the same work, it was reported that at a heating rate of $0.5{ }^{\circ} \mathrm{C} / \mathrm{s}$ in the studied steel, the temperature of total carbide dissolution in austenite and that for austenite homogenisation are $1110{ }^{\circ} \mathrm{C}$ and $1190{ }^{\circ} \mathrm{C}$, respectively. Therefore, at the former austenitisation temperature tested $\left(1060^{\circ} \mathrm{C}\right)$ carbides are partially dissolved in the austenite (5\% of carbides remain undissolved), whereas at the latter austenitisation temperature $\left(1200{ }^{\circ} \mathrm{C}\right)$, the totality of carbides have been dissolved during heating and austenite is expected to be homogeneous. Figure 3 shows scanning micrographs of microstructures obtained after heat treatment at 1060 and $1200{ }^{\circ} \mathrm{C}$ of austenitisation temperatures. The size and mean free path of carbides at $1060^{\circ} \mathrm{C}$ were determined on scanning electron micrographs as that shown in Fig. 3.a.

\section{RESULTS AND DISCUSSION}

Figure 4 shows a schematic representation of the dilatometric anomalies associated to the splitting phenomenon. $M_{s}$ in curve 1 represents the starting temperature of the martensitic transformation that takes place continuously throughout a single stage, whereas $M_{s i}$ in curve 2 is used to represent the temperature at which the principal martensite transformation starts as splitting phenomenon occurs. This temperature is identified by a minimum in the $\Delta L / L_{0}=f(T)$ dilatometric curve. Likewise, the starting temperature of the splitting stage occurring below $M_{s i}$ is represented by $M_{s o}$. This splitting stage is identified by an anomaly in the slope of the dilatometric curve. The weakness of this anomaly indicates that it is probably caused by the martensitic transformation of small areas of austenite enriched in carbon and/or carbide-forming elements. The cooling dilatometric curve corresponding to the austenitisation temperature of $1060{ }^{\circ} \mathrm{C}$ follows a behaviour similar to curve 2 in Fig. 4 with $M_{s i}=280{ }^{\circ} \mathrm{C}$ and $M_{s o}=234{ }^{\circ} \mathrm{C}$. By contrast, dilatometric behaviour during cooling from $1200{ }^{\circ} \mathrm{C}$ is more similar to curve 1 in Fig. 4; splitting phenomena are not display in the dilatometric curve and $M_{s}=158{ }^{\circ} \mathrm{C}$. As expected, this temperature is the lowest martensite transformation temperature for this steel since at $1200{ }^{\circ} \mathrm{C}$ the totality of carbides have been dissolved during heating and all the carbon and chromium are in solid solution in the austenite.

Microstructures after heat treatment at 1060 and $1200{ }^{\circ} \mathrm{C}$ were also examined using a JEOL JSM $6500 \mathrm{~F}$ field emission scanning electron microscope at $15 \mathrm{kV}$ on samples etched with Murakami's reagent to perform EDX analysis. The microscope is equipped with an energy disperse X-ray 7418 Oxford detector with a super ultra-thin window ATW2.

Figure 5.a shows scanning electron micrograph of a carbide in the steel after heat treatment at 1060 ${ }^{\circ} \mathrm{C}$. EDX analysis have been carried out at different points over the white line drawn in this figure. Fig. 5.b shows EDX spectra of the carbide (point A in Fig. 5.a) and of the matrix at a distance of 0.3 $\mu \mathrm{m}$ (point B in Fig. 5.a) and $0.9 \mu \mathrm{m}$ (point $C$ in Fig. 5.a) from the centre of the carbide. From this figure, it is clear that the chromium content in point $B$ is higher than in point $C$.

Graph in Fig. 5.c represents chromium, iron and carbon contents as a function of distance analysed between point $\mathrm{A}$ and point $\mathrm{C}$ over the white line in Fig. 5.a. The radius of the carbide in this figure is $0.2 \mu \mathrm{m}$. Chromium and iron contents are measured with an accuracy of \pm 0.2 and \pm 0.4 , 
respectively. The reliability of carbon content measurements is poor due to the difficulty of the equipment detecting light elements, but those results might be qualitatively useful. From Fig. 5.c, it seems that ahead the carbide-matrix interface, chromium content in austenite continuously decreases as the distance increases. Opposite behaviour is found regarding iron content in the austenite ahead the interface. By contrast, an homogenous profile of carbon is detected since the mobility of this element in austenite is high enough to homogenise the matrix as soon as carbide dissolves. At $1060{ }^{\circ} \mathrm{C}$ the diffusion coefficient of carbon $\left(8.010^{-7} \mathrm{~cm}^{2} / \mathrm{s}\right)$ is $10^{5}$ times higher than that for chromium $\left(2.710^{-12} \mathrm{~cm}^{2} / \mathrm{s}\right)$ and iron $\left(5.610^{-12} \mathrm{~cm}^{2} / \mathrm{s}\right)$ [8]. Additional EDX analysis of the matrix at a distance higher than $1 \mu \mathrm{m}$ from the centre of the carbide gave chromium, iron and carbon contents similar to those obtained at distances of 0.6 and $0.9 \mu \mathrm{m}$. It seems that the region of austenite around the carbides enriched in chromium does not extend further than $0.4 \mu \mathrm{m}$ from the carbide-matrix interface. The chromium content in the carbides and massive austenite at $1060{ }^{\circ} \mathrm{C}$ is given in Table 2. This results are average of 10 different point EDX analysis.

Therefore EDX analysis results show that areas of austenite with a higher concentration in chromium than the massive austenite surrounds the partially dissolved carbides at $1060{ }^{\circ} \mathrm{C}$ before quenching. The volume fraction of austenite enriched in chromium around the carbides can be roughly estimated from the size of carbides $(0.2 \mu \mathrm{m}$ in radius), the mean free distance between carbides (here $8 \mu \mathrm{m}$ ) determined from scanning electron micrographs, and the size of the enriched austenite region (hollow circles with $\sim 0.2 \mu \mathrm{m}$ of inner radius and $\sim 0.6 \mu \mathrm{m}$ of outer radius). Calculations indicate that $\sim 10 \%$ of austenite around the carbides is enriched in chromium in relation to the massive austenite phase at the austenitisation temperature of $1060{ }^{\circ} \mathrm{C}$. Likewise, the mean chromium content in the austenite around the carbides $\left(\bar{x}_{C r}^{\gamma+}\right)$ at this temperature can be estimated from the difference in chromium content between the carbide/austenite interface $\left(x_{C r}^{c a r b / \gamma+}\right)$ and the massive austenite $\left(x_{C r}^{\gamma}\right)$ (Fig. 5.d),

$\bar{x}_{C r}^{\gamma+}=\frac{x_{C r}^{c a r b / \gamma+}+x_{C r}^{\gamma}}{2}$

The chromium content at the carbide-matrix interface, $\left(x_{\mathrm{Cr}}^{\mathrm{carb} / \gamma+}\right)$, can be estimated from Judd and Paxton model for carbide dissolution in austenite [9] with the help of the following expression and the graph in Fig. 5.d,

$$
x_{C r}^{c a r b / \gamma+}=x_{C r}^{c a r b}-\frac{r_{o}^{3}-r_{\gamma+}^{3}}{r_{c a r b}^{3}-r_{o}^{3}} x_{C r}^{\gamma}
$$

where $x_{C r}^{c a r b}$ and $x_{C r}^{\gamma}$ are the chromium content in the carbide and the massive austenite, respectively (see data in Table 2), $r_{o}$ is the carbide radius before dissolution (here $0.45 \mu \mathrm{m}$ ), $r_{\gamma^{+}}$is the position in the austenite at which chromium content reaches homogeneity (i.e. $0.6 \mu \mathrm{m}$ ) and $r_{\text {carb }}$ is the position of carbide-matrix interface (i.e. $0.2 \mu \mathrm{m}$ ). Using equations (1) and (2), the values of $x_{C r}^{c a r b / \gamma+}=25.3 \pm 1.4$ wt- $\%$ and $\bar{x}_{C r}^{\gamma+}=18.4 \pm 2.7$ wt- $\%$ are obtained.

Therefore, at $1060{ }^{\circ} \mathrm{C}$ the steel is formed by a $5 \%$ of carbides, a $10 \%$ of enriched austenite with a mean chromium content of $18.4 \pm 2.7 \mathrm{wt}-\%$, and a $85 \%$ of massive austenite with a chromium content of $11.6 \pm 1.3 \mathrm{wt}-\%$. In this austenitising state, a difference of $46{ }^{\circ} \mathrm{C}$ is detected between $M_{s i}$ and $M_{s o}$ in the dilatometric test. Likewise, a similar order of magnitude is theoretically estimated for the difference in temperature between $M_{s i}$ and $M_{s o}$. Thus, according to artificial neural network model developed by the authors [10] and considering a chromium content in the massive austenite, $x_{C r}^{\gamma}$, of $11.6 \pm 1.3 \mathrm{wt}-\%$, and a mean chromium content in the austenite around the carbides, $\bar{x}_{C r}^{\gamma+}$, of 18.4 \pm 2.7 wt-\%, the difference in temperature between $M_{s i}$ and $M_{s o}$ is, 


$$
M_{s i}-M_{s o}=-8.9 \cdot\left(x_{C r}^{\gamma}-\bar{x}_{C r}^{\gamma+}\right)=61 \pm 4{ }^{\circ} \mathrm{C}
$$

Finally, graph in Fig. 6 represents chromium, iron and carbon contents as a function of distance analysed between two random points separated by a distance of $2.7 \mu \mathrm{m}$ in the steel after heat treatment at $1200{ }^{\circ} \mathrm{C}$ (Fig. 3.b). The chromium content in the austenite at $1200{ }^{\circ} \mathrm{C}$ is also given in Table 2. An homogenous profile is detected for the three elements at this austenitisation temperature and as it was mentioned above, splitting phenomenon was not detected on the cooling dilatometric curve corresponding to the austenitisation temperature of $1200{ }^{\circ} \mathrm{C}$ of this steel.

All these results allow us to conclude that the splitting phenomenon detected on the cooling dilatometric curve corresponding to the austenitisation temperature of $1060{ }^{\circ} \mathrm{C}$ is caused by the chromium concentration gradient produced in the austenite from the partial dissolution of carbides during heating.

\section{Conclusions}

This work has shown experimental evidences that prove the origin of the splitting phenomena occurring in the martensitic transformation of stainless steels. In the absence of carbide precipitation and from austenitising states in which austenite has not reached homogenisation because the carbide dissolution process has not finished, austenite-martensite transformation will experience splitting phenomena at temperatures lower than the main martensitic transformation. This splitting indicates the existence of areas of austenite that are enriched in chromium in relation to the massive austenite phase.

\section{$\underline{\text { Acknowledgements }}$}

The authors acknowledge financial support from Spanish Ministerio de Ciencia y Tecnología (MAT2000-0412-P4-02). C. Capdevila would like to express his gratitude to the Consejo Superior de Investigaciones Cientifícas for financial support as a Post-Doctoral contract (I3P PC-2001-1). F.G. Caballero would like to thank Spanish Ministerio de Ciencia y Tecnología for the financial support in the form of a Ramón y Cajal contract (Programa RyC 2002).

\section{$\underline{\text { References }}$}

[1] Kulmburg A, Korntheuer F. Hartereitechniche Mitteilungen (HTM) 1976;31:195.

[2] Maratray J, Poulation A. Contribution à L'étude du Contrôle des Structures et de Leur Dureté Dans les Alliages Ferreux à Hautes Teneurs en Carbone et en Chrome. Paris: Climax Molybdenum; 1977. p. 1.

[3] Vaugeois P. Caractérisation du Comportement Structural d'un Acier Rapide a Fortes Teneurs en Cobalt et en Vanadium du Type Z125WKVD9. 9.3.3. Thèse $3{ }^{\text {ème }}$ Cycle. Orsay: Université Paris-Sud; 1984. p. 20.

[4] Freire Vieira MT. Tratermat'86, Tomo II, Proc. II Congreso Nacional de Tratamientos Térmicos. San Sebastian: Inasmet; 1986. p.48.

[5] García de Andrés C, Jimenez JA, Alvarez LF. Metall. Mater. Trans. A 1996;27:1799.

[6] MTDATA: Phase diagram calculation software. Teddington: National Physical Laboratory; 2003.

[7] García de Andrés C, Álvarez LF. J. Mater. Sci. 1993;28:1264.

[8] Honeycombe RWK, Bhadesia HKDH. Steels. Microstructure and Properties, $2^{\text {nd }}$ Edition. London: Edward Arnold; 1995. p.7. 
[9] Judd RR, Paxton HW. Transactions of the Metallurgical Society of AIME 1968;242:206.

[10] Capdevila C, Caballero FG, García de Andrés C. ISIJ International 2002;42:894. 


\section{Figure Captions}

Figure 1.- Optical micrographs of the steel in as-received condition: a) Etched in Vilella'reagent and b) Etched in Murakami’s reagent.

Figure 2.- Volume fraction of carbides present in the microstructure according to thermodynamic equilibrium calculations.

Figure 3.- Scanning electron micrographs of the steel after heat treatment at a) $1060{ }^{\circ} \mathrm{C}$ and b) $1200{ }^{\circ} \mathrm{C}$.

Figure 4.- Dilatometric scheme of the splitting phenomenon in the martensitic transformation.

Figure 5.- a) Scanning electron micrographs of carbides present in the microstructure after heat treatment at $1060{ }^{\circ} \mathrm{C}$; b) EDX analysis results at A, B and C points; c) Iron, chromium and carbon contents as a function of distance between A and C points; the shaded area in this graph represents the uncertainty in carbon content results; and d) Chromium profile considered to calculate the mean chromium content in the enriched austenite.

Figure 6.- Iron, chromium, and carbon contents as a function of distance analysed between two random points in the steel after heat treatment at $1200{ }^{\circ} \mathrm{C}$ (Fig. 3.b). The shaded area in this graph represents the uncertainty in carbon content results 
Tables

Table 1

Chemical Composition (weight \%)

\begin{tabular}{ccccccc}
\hline $\mathbf{C}$ & $\mathbf{C r}$ & $\mathbf{N i}$ & $\mathbf{S i}$ & $\mathbf{M n}$ & $\mathbf{P}$ & $\mathbf{S}$ \\
\hline 0.45 & 13.0 & 0.38 & 0.32 & 0.44 & 0.03 & 0.016 \\
\hline
\end{tabular}

Table 2

Quantitative EDX analysis results (weight \%)

\begin{tabular}{lc}
\hline \multicolumn{1}{c}{ Analysis } & Cr \\
\hline Carbide, $x_{C r}^{\text {carb }}$ & $42.7 \pm 0.1$ \\
Massive austenite at $1060^{\circ} \mathrm{C}, x_{C r}^{\gamma}$ & $11.6 \pm 1.3$ \\
Massive austenite at $1200^{\circ} \mathrm{C}$ & $13.1 \pm 0.1$ \\
\hline
\end{tabular}




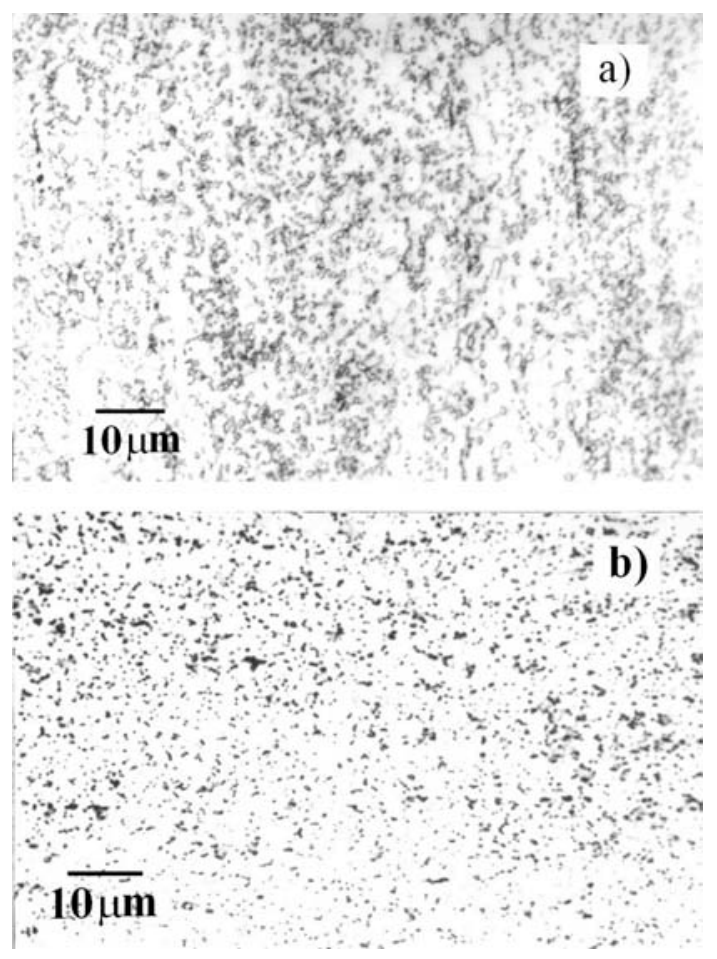

Figure 1 


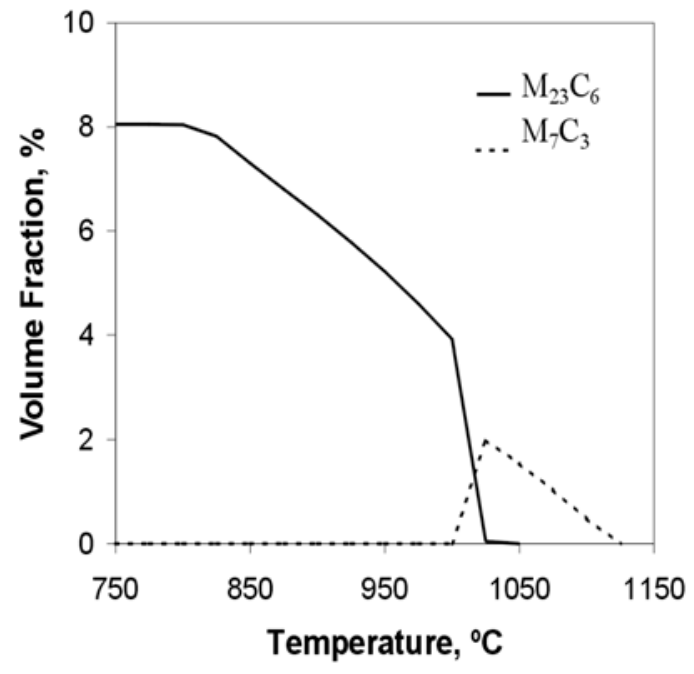

Figure 2 


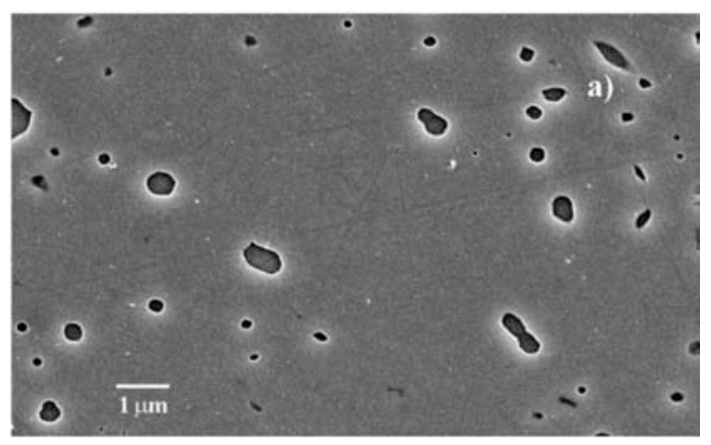

$0.5 \mu \mathrm{m}$

Figure 3 


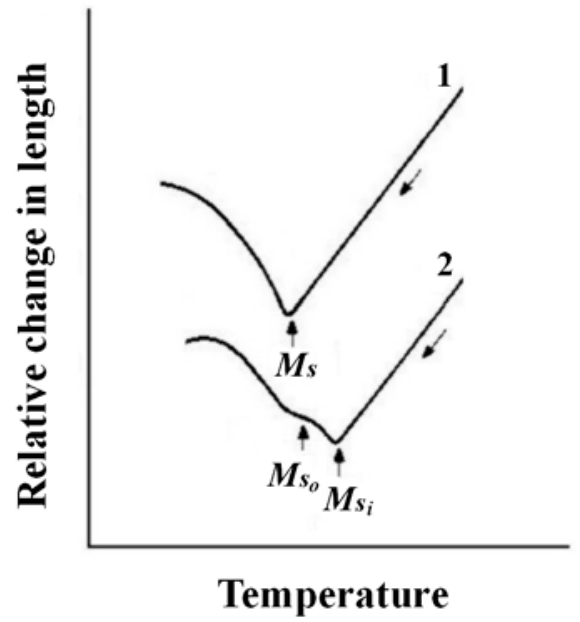

Figure 4 

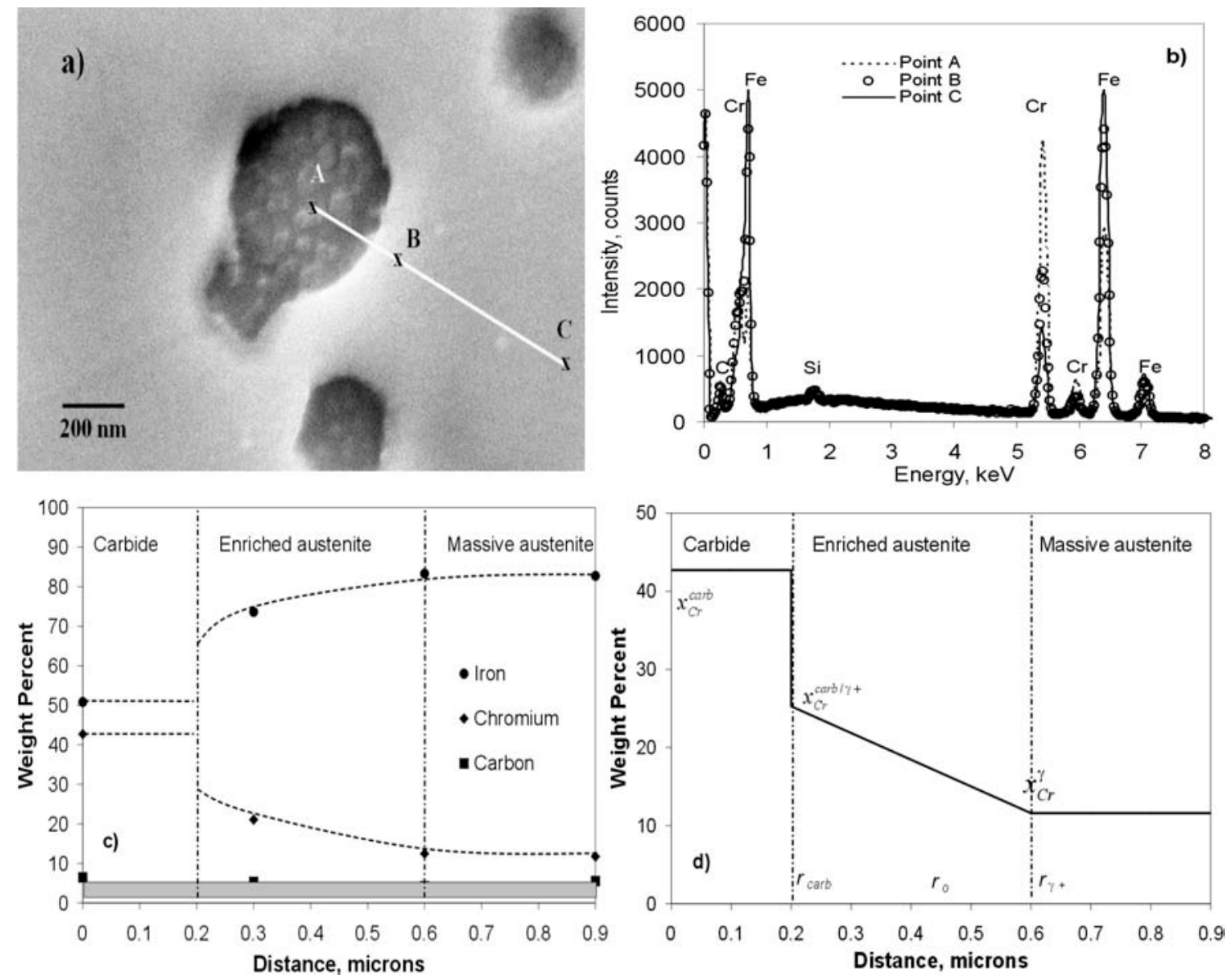

Figure 5 


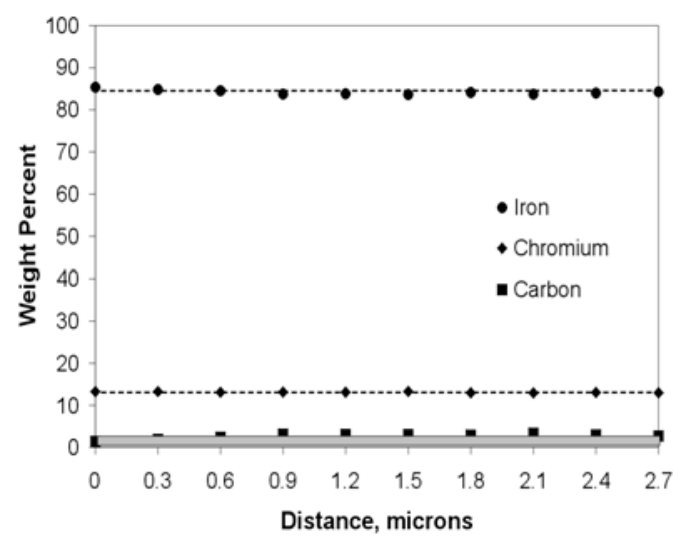

Figure 6 